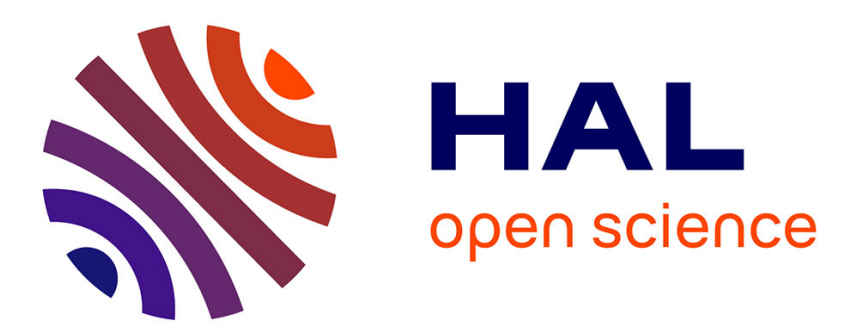

\title{
Mechanical properties and molecular structures of virgin and recycled HDPE polymers used in gravity sewer systems
}

\author{
Mathias Alzerreca, Michael Paris, Olivier Boyron, Dominique Orditz, Guy \\ Louarn, Olivier Correc
}

\section{To cite this version:}

Mathias Alzerreca, Michael Paris, Olivier Boyron, Dominique Orditz, Guy Louarn, et al.. Mechanical properties and molecular structures of virgin and recycled HDPE polymers used in gravity sewer systems. Polymer Testing, 2015, 46, pp.1 - 8. 10.1016/j.polymertesting.2015.06.012 . hal-01725496

\author{
HAL Id: hal-01725496 \\ https://hal.science/hal-01725496
}

Submitted on 11 Nov 2019

HAL is a multi-disciplinary open access archive for the deposit and dissemination of scientific research documents, whether they are published or not. The documents may come from teaching and research institutions in France or abroad, or from public or private research centers.
L'archive ouverte pluridisciplinaire HAL, est destinée au dépôt et à la diffusion de documents scientifiques de niveau recherche, publiés ou non, émanant des établissements d'enseignement et de recherche français ou étrangers, des laboratoires publics ou privés. 


\section{Accepted Manuscript}

Mechanical properties and molecular structures of virgin and recycled HDPE polymers used in gravity sewer systems

Mathias Alzerreca, Michael Paris, Olivier Boyron, Dominique Orditz, Guy Louarn, Olivier Correc

PII:

$$
\text { S0142-9418(15)00144-0 }
$$

DOI:

Reference:

POTE 4458

To appear in: Polymer Testing

Received Date: 18 May 2015

Accepted Date: 24 June 2015

Please cite this article as: M. Alzerreca, M. Paris, O. Boyron, D. Orditz, G. Louarn, O. Correc, Mechanical properties and molecular structures of virgin and recycled HDPE polymers used in gravity sewer systems, Polymer Testing (2015), doi: 10.1016/j.polymertesting.2015.06.012.

This is a PDF file of an unedited manuscript that has been accepted for publication. As a service to our customers we are providing this early version of the manuscript. The manuscript will undergo copyediting, typesetting, and review of the resulting proof before it is published in its final form. Please note that during the production process errors may be discovered which could affect the content, and all legal disclaimers that apply to the journal pertain. 
Material Properties

\title{
Mechanical properties and molecular structures of virgin and recycled HDPE polymers used in gravity sewer systems
}

Mathias Alzerreca ${ }^{\mathrm{a}, \mathrm{b}}$, Michael Paris ${ }^{\mathrm{b}}$, Olivier Boyron ${ }^{\mathrm{c}}$, Dominique Orditz ${ }^{\mathrm{a}}$, Guy Louarn ${ }^{\mathrm{b} *}$, Olivier Correc ${ }^{\mathrm{a}}$.

a. Centre Scientifique et Technique du Bâtiment (CSTB), Aquasim, 11 rue Henri Picherit, 44300 Nantes (France)

b. Institut des Matériaux Jean Rouxel (IMN) ; CNRS-Université de Nantes

BP32229, 2 rue de la Houssinière, Nantes 44322 (France)

c. Université de Lyon, Univ. Lyon 1, CPE Lyon, CNRS UMR 5265, Laboratoire de Chimie Catalyse Polymères et Procédés (C2P2), Equipe LCPP, Bat 308F, 43 Bd du 11 Novembre 1918, 69616 Villeurbanne (France)

\begin{abstract}
The widespread use of plastics in the conditioning, packaging and building material sectors generates an enormous amount of industrial waste which could be recycled for wastewater pipes and fittings. Nevertheless, current manufacturing standards in the piping industry recommend against the use of post-consumer recycled materials-a policy based on inadequate understanding of the properties and long-term mechanical performance of recycled materials. The present study compared the material characteristics of virgin and recycled high-density polyethylene (HDPE) plastics commonly found in the piping industry. Mechanical testing, oxidative induction time (OIT), melt flow index (MFI) and thermal analysis were used in conjunction with X-ray fluorescence $(\mu$-XRF), size exclusion chromatography and ${ }^{13} \mathrm{C}$ solid-state $\mathrm{NMR}$ to evaluate mechanical behavior and molecular structure as well as contaminant or filler contents. This study provides evidence for the degradation processes impact that can occur when post-industrial and post-consumer polymers are recycled. However, the study identified two measures to improve the material qualities of post-consumer recycled HDPE: 1) reducing the amount of contaminants or, alternatively, improving their compatibility with HDPE resins, and 2) improving current sorting and recycling processes to increase the amount of tie molecules in HDPE materials.
\end{abstract}


Keywords : Polyethylene, post-consumer, pipe, lifetime, creep, fatigue, GPC, solid-state NMR

Corresponding author. Tel.: +33 (0) 240376 327; fax: +33 (0) 240373991 E-mail address: Guy.louarn@cnrs-imn.fr (G. Louarn).

\section{Introduction}

According to a recent economic study, the European Union produces 45.9 million tons of plastics in 2012; polyethylene accounted for $29.5 \%$ (PE) and polypropylene (PP) for $18.8 \%$ $[1,2]$. Polyolefins in particular constitute a significant percentage of household waste: $40 \%$ of all polyolefin-derived products are considered to have a short service life; and $38 \%$ of these products end up in landfills. Although polyolefin plastics can be mechanically recycled, regenerated or incinerated, they do not decompose under natural conditions-a cause for considerable environmental concerns. Plastic manufacturers have begun to recycle their waste products in an attempt to address this problem. For example, the startup, breakdowns, and general quality problems that may occur during the manufacture of plastic articles contribute to the amount of generated "post-manufacturer" waste. These waste products can be recycled internally or transferred to specialized plastic recyclers for further processing into reusable pellets. Similarly, the recycling of post-consumer plastics can offer an opportunity to reduce the amount of wasted plastic material and could save energy and raw materials for future generations.

However, certain economic and technical factors must be considered to evaluate the feasibility of recycling plastics. For example, polymer degradation and the unavoidable introduction of contaminants during the sorting, washing, repelletizing and reprocessing steps can cause manufacturing problems resulting in finished products of inferior quality. Current research in this field seeks to optimize and improve the properties of recycled polymers, especially those of polyolefin.

High density polyethylene (HDPE) is used extensively in the production of water pipes; such HDPE pipes are made from custom-engineered polyethylene materials with unique properties. The following requirements apply to pressure pipes that are mainly used for drinking water: the material must 1) be of food-grade quality, 2) have considerable pressure resistance, and 3) guarantee a minimum service lifetime of 50 years. A suitable pipe resin for 
the production of pressure pipes should offer an optimum combination of these properties. An HDPE resin formulated according to these requirements must include a polymer blend or polymer alloy containing both a low-molecular-weight homopolymer fraction and a highmolecular-weight copolymer fraction. At the time of writing, the highest standard is the PE100 class. The PE100 standard specifies that highest quality pressure pipes made from such materials must withstand a hoop stress of $10 \mathrm{MPa}$, for 50 years at room temperature [3].

In contrast, the mechanisms involved in long terms degradation and malfunctions of HDPE gravity sewer pipes are radically different from those affecting pressure pipes [4]. In fact, in the wastewater gravity pipes, fluids flow downwards by gravity and may contain harmful chemical products and biochemical residues. Because of their most important properties - a specific creep ratio and stiffness combined with a service lifespan of 50 yearssewer pipes have different mechanical and chemical constraints compared with pressure pipes. The molecular design of appropriate polymers needs to consider these requirements, and polymer performance standards should be adapted accordingly. If at present the use of recycled polymers seems incompatible with the long-term performance expected of pressure pipes, one must consider that the material can instead be used in the manufacture of sewer pipes.

The present study compared virgin, reprocessed and recycled HDPE, provided by manufacturers of plastic pipes. Mechanical testing (creep and fatigue) was used to assess the effects of degradation processes that can occur in the reprocessing of post-industrial (internally or externally reprocessed) and post-consumer (recycled) polymers. In addition, size-exclusion chromatography, ${ }^{13} \mathrm{C}$ solid-state NMR, thermal analysis (TGA and DSC), and oxidative induction time (OIT) and melt flow index (MFI) measurements were used to analyze the short-term and long-term evolution of the mechanical properties of these materials. Additionally, the presence of contaminants and/or catalytic residues in the recycled and regenerated HDPE was examined using X-ray fluorescence ( $\mu$-XRF) and energy dispersive X-ray spectroscopy (EDS). The gathered data were then used to explain the pipe's resistance and ability to withstand various types of imposed service conditions, and attempt to answer the question: Are pipes made from post-consumer recycled HDPE able to achieve the level of performance required by industry standards?

\section{Materials}


The present study was part of a larger program to explore the applications of reprocessed and recycled HDPE in the production of sewer pipes. Note that extrusion-ready granules containing antioxidants and additives were used deliberately in the experiments because they correspond to the type of granules used in the production line. The samples were injection molded from a single batch of the respective HDPE material. The molded test samples were then divided into four groups and used as follows:

1) The first group was made from virgin high-density polyethylene - a high quality PE 100 (according to ISO 4427) typically used for pipe extrusion. This polymer has a bimodal molecular mass distribution; the grade selected for the experiments is well known for its good resistance to long-term loading and extremely high resistance to rapid cracking.

2) The second group (HDPE-R) consisted of an HDPE that was reprocessed from granulated post-industrial waste (recycled from defective or damaged products). Antioxidants were introduced to stabilize the industrial polymer before reprocessing.

3) The third group (HDPE-M) was a mix of high-quality virgin HDPE granules and reprocessed material of unknown origin; it contained a minimum of $80 \%$ virgin polymers.

4) The fourth group (HDPE-P) contained the recycled batch produced from household waste (milk, bleach and cleaning product bottles) collected at a reprocessing plant. The collected HDPE was first shredded at the plant, washed, and then reformulated (stabilized) and granulated by a pipe manufacturer.

\section{Experimental process}

\section{Injection molding}

Granulated material was reprocessed through injection molding. The material was used in its as-received state and injection molded into dumbbell shaped samples according to AFNOR standards (NF ISO EN 527-2 with type 1A dimensions) with an injection-molding machine (DK Technologies, NGH series, France).

\section{Size exclusion chromatography}

High temperature size exclusion chromatography (HT-SEC) analyses were performed using a Viscotek system (from Malvern Instruments) equipped with a combination of three columns (Polefin $300 \mathrm{~mm}$ x 8 mm I. D. from Polymer Standards Service, porosity of $1000 \AA$, $100000 \AA$ and $1000000 \AA$ ). Samples were dissolved in the mobile phase with a 
concentration of $5 \mathrm{mg} \cdot \mathrm{mL}^{-1} .200 \mu \mathrm{L}$ of sample solutions were injected and eluted in 1,2,4trichlorobenzene using a flow rate of $1 \mathrm{~mL} \cdot \mathrm{min}^{-1}$ at $150^{\circ} \mathrm{C}$. A universal calibration curve, obtained with polystyrene standards (Polymer Standards Service, Mainz, Germany) in the range of 500 to $7 \times 10^{6} \mathrm{~g} \cdot \mathrm{mol}^{-1}$, was used to calculate the molar mass distribution of the samples.

\section{Oxidation induction time}

The oxidation induction time (OIT) of the HDPE samples $(13 \pm 2 \mathrm{mg})$ was determined with a differential scanning calorimeter (DSC) (model Q200, TA instruments, New Castle, USA) equipped with an open aluminum sample pan. Using nitrogen at a flow rate of 50 $\mathrm{mL} / \mathrm{min}$, the cell temperature was increased from 50 to $200{ }^{\circ} \mathrm{C}$ at a rate of $20{ }^{\circ} \mathrm{C} / \mathrm{min}$; this final temperature was held constant for 3 min before switching to pure oxygen at a flow rate of $50 \mathrm{~mL} / \mathrm{min}$. The onset of sample oxidation was determined according to standard AFNOR procedure NF EN 728.

\section{Melt flow index}

Melt flow index tests were carried out with a plastometer (LMI 4000 series melt flow indexer, Dynisco, Franklin, USA) at $190{ }^{\circ} \mathrm{C}$ under a static load of $5 \mathrm{~kg}$ according to the NF EN ISO 1133 (2005) standard.

\section{$\underline{\text { Analysis of metal residue }}$}

$\mathrm{X}$-ray fluorescence $(\mu-\mathrm{XRF})$ analysis of the injection-molded samples was performed with an M4 Tornado (Bruker Corp., Billerica, USA) using a rhodium filament excited at 30 $\mathrm{kV}$ and $200 \mu \mathrm{A}$. X-ray photoelectron spectroscopy (XPS) measurements were carried out at room temperature on an AXIS Nova spectrometer (Kratos Analytical, Manchester, UK) using the $\mathrm{Al} \mathrm{K}$ line $(1486.6 \mathrm{eV})$ as the excitation source. The data were registered on a freshly prepared section (cut with a blade) of the sample. A Thermo Nicolet Nexus FTIR spectrometer with a Smart MIRacle accessory equipped with a diamond crystal (Thermo Fisher Scientific, Waltham, USA) was used for ATR-FT-IR spectroscopy.

\section{$\underline{\text { NMR measurements }}$}

Both nuclear magnetic resonance (NMR) spectra-the ${ }^{13} \mathrm{C}$ single pulse excitation and $\left\{{ }^{1} \mathrm{H}\right\}-{ }^{13} \mathrm{C}$ CP-MAS (Cross-Polarization and Magic Angle Spinning)—were acquired on a Bruker $500 \mathrm{MHz}$ Avance III spectrometer using a $4 \mathrm{~mm}$ CP-MAS probe. In all cases, the MAS frequency was set to $14 \mathrm{kHz}$ and an optimized ${ }^{1} \mathrm{H}$ decoupling (TPPM scheme in ref [5]) 
of $88 \mathrm{kHz}$ radio-frequency field (RF) strength was used. The $\left\{{ }^{1} \mathrm{H}\right\}-{ }^{13} \mathrm{C} \mathrm{CP}-\mathrm{MAS}$ spectra were acquired with contact time of $2 \mathrm{~ms}$ and a ${ }^{1} \mathrm{H}$ recycle time of $3 \mathrm{~s}$. For quantitative purpose, the single pulse excitation ${ }^{13} \mathrm{C}$ MAS spectra were obtained with a $\pi / 4$ excitation pulse (RF strength of $56 \mathrm{kHz}$ ) and a ${ }^{13} \mathrm{C}$ recycle time of $240 \mathrm{~s}$. Spectra were referenced to tetramethylsilane using the $29.5 \mathrm{ppm}$ resonance of adamantane.

\section{Mechanical characterization}

All mechanical tests were conducted with an MTS 20/MH electromechanical universal testing machine equipped with a 2-kN load cell (MTS Systems, Eden Prairie, USA). The dumbbell shaped samples (ISO 527-2 [2012] type 1A, gauge length $75 \mathrm{~mm}$, distance between grips $115 \mathrm{~mm}$ ) were tested in a uniaxial tensile configuration under a constant crosshead speed of $50 \mathrm{~mm} / \mathrm{min}$. An MTS EX34 clip-on extensometer with a gauge length of $75 \mathrm{~mm}$ (MTS Systems) was used to determine the tensile modulus at a crosshead speed of $1 \mathrm{~mm} / \mathrm{min}$ with a strain of between 0.05 and $0.25 \%$. Fatigue and creep tests were performed with a servo hydraulic testing machine using a load-controlled sinusoidal cycle.

\section{Results}

The mechanical properties of a PE pipe-such as its molecular weight, molecular weight distribution, degree of branching (density) of the polymer, as well as the type and quantity of incorporated additives or flaws - are largely determined by the PE source material used to make the pipe [6-8]. Therefore, the present study characterized the main mechanical properties of virgin, reprocessed and recycled HDPE. In addition, the physicochemical properties and the presence of contaminants were investigated to identify potential discrepancies between the short- and long-term experiments.

\section{Mechanical properties}

Pipes must withstand short-term and long-term loads. However, important differences between short-term and long-term characteristics prevent the use of short-term experimental data to predict long-term performance. Under short-term loads, polyethylene typically reacts in a resilient, ductile-elastic manner. So, short-term mechanical tests are characterized by the ductile elongation (necking down and cold drawing) and then the failure in the elongated area. These characteristics may be described in terms of the viscoelasticity of polymers, which includes the rate of molecular chain motion and the role of chain entanglements. Although the motion of chain molecules may be implicated, long-term ultimate strength is mainly 
determined by the appearance of crazing and the formation of slowly growing stress cracks that travel through the pipe wall (slow crack growth) [9]

Characteristic values of the tensile stress-strain curves were recorded for each HDPE sample both at low and at high levels of deformation (Table 1). At room temperature, HDPE specimens were ductile under tension, showing first necking and drawing followed by slightly elongated rupture. As reported in table 1, it is seen that the strain at break, yield strength and tensile strength were different for each recycled polymer. For instance, concerning the ultimate tensile strength, the value for the virgin material was about $30.5 \mathrm{MPa}$ whereas it decreased to 26.7 MPa for HDPE-R and HDPE-M and to 24.8 MPa for HDPE-P, respectively. The Young's modulus was determined according to the procedure described in the ISO 527 standard, which yielded values in the range of 670 to $935 \mathrm{MPa}$. However, a pronounced nonlinear behavior was noticeable. For example, the elongation rate observed in the test had a significant effect on tensile properties $[10,11]$. The Young's modulus measured using tensile curves at $50 \mathrm{~mm} / \mathrm{min}$ was, therefore, significantly higher (up to $1250 \mathrm{MPa}$ for PE100, a). Similarly, total elongation varied between 13 and $76 \%$ depending on the grade of the polymer.

\section{Table 1}

Table 1. Mechanical characteristics and sample codes of the studied HDPE materials

\begin{tabular}{cccccc}
\hline Sample code & $\begin{array}{c}\text { Young's Modulus } \\
(\mathbf{M P a})\end{array}$ & $\begin{array}{c}\text { Yield strength } \\
(\mathbf{M P a})\end{array}$ & $\begin{array}{c}\text { strain at } \\
\text { break } \\
(\%)\end{array}$ & $\begin{array}{c}\text { Strain at } \\
\text { ultimate stress }\end{array}$ \\
\hline PE100, a & $750( \pm 23)$ & $30.5( \pm 0.7)$ & $13 \%( \pm 1)$ & $9.1 \%( \pm 0.2)$ \\
HDPE-M, b & $935( \pm 40)$ & $26.7( \pm 0.2)$ & $22 \%( \pm 1)$ & $9.1 \%( \pm 0.2)$ \\
HDPE-R, c & $870( \pm 34)$ & $26.7( \pm 0.3)$ & $23 \%( \pm 3)$ & $9.6 \%( \pm 0.3)$ \\
HDPE-P, d & $670( \pm 49)$ & $24.8( \pm 0.2)$ & $76 \%( \pm 16)$ & $10.5 \%( \pm 0.1)$ \\
\hline
\end{tabular}

Results indicated that the recycling process decreased the tensile strength but increased the plasticity of the produced HDPE plastics. Changes in the molecular weight and in the crystallinity ratio could be responsible for this material alteration (discussed hereafter).

In polyethylene, the strength under load depends also on the magnitude of the load and the duration that the load is applied. For instance, during creep and fatigue experiments, elongation occurs by molecular motions (linear chains under stress) associated with the formation and growth of crazes, which then cracks [9]. In this work, creep experiments were 
conducted as following: a constant stress $\sigma$ is applied to a sample, and the strains $\varepsilon(t, \sigma)$ are recorded as a function of time. Creep experiments are reported as the time-dependent compliance, $J(t)[J(t)=\varepsilon(t, \sigma) / \sigma]$.

Figure 1 shows representative creep compliance curves for various HDPE samples at $800 \mathrm{~N}$. Note that these conventional creep tests measured changes in length of a specimen under a constant load as a function of experiment time. Because section length decreased under load, internal stress within the specimens continued to increase during the creep tests [12]. Evidently, reprocessed and recycled HDPE both presented a markedly lower creep compliance compared with non-recycled PE100. These results clearly showed that the creep compliance of the recycled HDPE was inferior to that of post-industrial reprocessed HDPE. This observation is consistent with the evolution of the elongation that was measured at break during the tensile tests of the HDPE samples. The paper's Discussion section considers the molecular motion under load as well as the presence of contaminants, especially in postconsumer recycled HDPE.

\section{Figure 1.}

Fatigue experiments on the recycled HDPE have been investigated. During service, the materials are subjected to cyclic load fluctuations so it is important to analyze their resistance to crack growth under cyclic loading. It should be stressed here that the effects of test frequency and the temperature on fatigue crack growth rate is complex [13-14]. For practical reasons, the present comparative study used fixed parameters: a temperature of $26^{\circ} \mathrm{C}$, an Rratio (defined as the ratio of the minimum stress to the maximum stress in the fatigue loading cycle) of 0.1 with constant maximum load intensities of 700, 760, 840, and $900 \mathrm{~N}$, and a loading frequency of $2 \mathrm{~Hz}$.

Figure 2 shows changes in the crosshead displacement observed during fatigue testing. Observations showed that the cracks did not grow in the stepwise fashion that results from sequential crazing [13]. A possible explanation for this absence of stepwise cracking could be that the crack growth rate comprised superimposed fatigue and creep effects [13]. The creep contribution for the experimental conditions of the conducted fatigue tests was probably not negligible. The crosshead displacement increased (Fig. 2-A) in conjunction with gradually progressing damage that relieved stress concentrated at the tip of the crack. Failure ultimately occurred because voids successively formed in the specimen and then coalesced. Experiments using post-consumer recycled HDPE were stopped after about 13,000 cycles (2 hours) following material rupture. In contrast, the virgin PE100 specimens were still intact when the 
test was switched off after 315,000 cycles (44 hours). This result is fully consistent with the specifications of the PE100 grade - a bimodal polyethylene of the latest generation with optimized mechanical properties and resistance to both slow and rapid crack growth. For HDPE-R and HDPE-M, rupture occurred after about 30,000 and 80,000 cycles, respectively. These results highlight the inferior fatigue test performance of recycled polymers. The findings were confirmed by plotting the magnitude of the cyclic stress against the number of cycles to failure (Fig. 2-B).

\section{Figure 2.}

\section{Chemical properties}

As a consequence of the degradation that may have occurred during the previous service life of the material, and because of potentially introduced defects and contaminants, reprocessed and recycled plastics are expected to exhibit a lower mechanical performance than plastics made from virgin raw materials. For instance, contact with oxygen and other chemicals can modify the molecular structure. Recycled PE generally has a higher concentration of hydroperoxide and peroxide groups, which can alter polymer stability and lifetime significantly. Moreover, the recycling process often causes changes in the molecular weight of the polymer because of cross-linking or chain scission. Finally, it has been established that surface defects and solid particles of residual catalysts or mineral fillers can initiate surface cracks in the material; such cracks drastically decrease creep compliance [15].

The present study used micro-X-ray fluorescence spectroscopy, X-ray photoelectron spectroscopy (XPS), and scanning electron microscopy coupled with energy dispersive X-ray spectroscopy (SEM/EDX) to detect and characterize metallic residues and other inorganic contaminants in the recycled HDPE. Metallic residue and inorganic filler concentrations were estimated in parts per million for the total sample (carbon) using quantitative $\mu$-XRF and semi-quantitative XPS (Fig. 3). This relative quantification revealed that the metals Ti and Ca were the main contaminants (Table 2). Residual fillers and pigments, such as titanium oxide added to obtain white thermoplastics, as well as, to a lesser degree, catalytic residues may be responsible for the high $\mathrm{Ti}$ concentration of around $5000 \mathrm{ppm}$ in recycled HDPE. This assumption was confirmed through the EDX analysis (Fig. 3-A), which revealed the presence of $\mathrm{Ti}$ and oxygen in the same area (micro and nanoparticles embedded in the polymers). The presence of calcium carbonate was predictable because it is a common filler substance in thermoplastics. Various other metals were also detected (e.g., Fe and Zn). The SEM images 
showed the characteristic distributions of titanium and calcium carbonate particles, which ranged from 0.2 to $2 \mu \mathrm{m}$ in size (Fig. 3-A).

Figure 3 .

Table 2. Quantitative analysis of contaminants and residual fillers for various HDPE samples

\begin{tabular}{|c|c|c|c|c|c|c|c|}
\hline \multirow{2}{*}{ Sample code } & \multirow{2}{*}{$\begin{array}{l}\mathrm{PP}^{\mathrm{a})} \\
\mathrm{wt} \%\end{array}$} & \multicolumn{2}{|c|}{$\mathrm{BC}^{\mathrm{b})}$} & \multicolumn{4}{|c|}{$\operatorname{Metal}\left(\mathrm{ppm}^{\mathrm{c})}\right)$} \\
\hline & & wt $\%$ & $\mathrm{Ti}$ & $\mathrm{Ca}$ & $\mathrm{Fe}$ & $\mathrm{Zn}$ & Traces $(<2 \mathrm{ppm})$ \\
\hline PE100 & $<0,1$ & 1.9 & - & 36 & 3 & & $\mathrm{Ti}, \mathrm{K}$ \\
\hline HDPE-M & $<0,1$ & 3.3 & 130 & 125 & 47 & 29 & $\mathrm{Si}, \mathrm{Cu}, \mathrm{P}, \mathrm{S}, \mathrm{Cu}$, \\
\hline HDPE-R & $<0,1$ & 1.0 & 4100 & 2500 & 100 & 64 & $\mathrm{Si}, \mathrm{P}, \mathrm{S}, \mathrm{Cu}$ \\
\hline HDPE-P & $2-3$ & 0.9 & 5400 & 1100 & 78 & & $\mathrm{Zn}, \mathrm{Cu}, \mathrm{Si}, \mathrm{S}, \mathrm{Al}$ \\
\hline
\end{tabular}

a) Polypropylene content based on solid-state ${ }^{13} \mathrm{C}-\mathrm{NMR}$ spectra

${ }^{b)}$ Black carbon content quantified through TGA analysis using a nitrogen atmosphere

${ }^{c)}$ Parts per million

The black carbon content (mass fraction in weight percent) of virgin PE, HDPE-R, and HDPE-P was nearly identical; HDPE-M contained significantly higher amounts. Although the exact composition of the HDPE-M sample was unknown, the elevated amount of black carbon (which was probably added to improve the material's initial mechanical properties) suggests than more carbon black was added to improve the initial mechanical properties and that the sample contained about 5 to $10 \%$ of reprocessed PE (estimation from Ti the and $\mathrm{Ca}$ contents).

In the waste stream, small amounts of polypropylene are frequently found blended with HDPE matrix composites: These two polymers, which are often used together in manufacturing products, cannot be completely separated from each other despite recent progress in automatic waste sorting. Microscopic and calorimetric analyses have shown that $\mathrm{PE}$ and PP are immiscible. This blend thus exists as a two-phase mixture in which PP is heterogeneously dispersed in the continuous PE matrix [16]. The poor interfacial bond strength between both phases could, therefore, explain the inferior mechanical properties of these blends [17]. FTIR scans can be used to estimate the PP content of both virgin and recycled HDPE blends. Unfortunately, the low intensity of the characteristic bands for PP/HDPE blends with PP concentrations of less than $2 \mathrm{wt} \%$ leads to inaccurate quantification. In addition, the presence of additives, antioxidants, stabilizers and carbon black in PE pipes can reduce the sensitivity of this technique and make it difficult to derive information from such measurements. Similarly, attempts to determine polypropylene concentrations lower 
than 1 or 2 wt\% in the HDPE matrix through thermal analysis (DSC) proved difficult and were often inaccurate. It was thus necessary to use a complex sampling procedure to obtain representative batch data. NMR spectroscopy is a very powerful technique that can be used to identify changes in the molecular structure, describe these changes (branching, etc.) and detect the presence of organic contaminants $\left({ }^{1} \mathrm{H}\right.$ - and ${ }^{13} \mathrm{C}$ - in the solid state HDPE). Figure 4 shows the solid-state ${ }^{13}$ C-CPMAS spectra of PE100, HDPE-R, and HDPE-P. The clearly visible bands in the HDPE-P spectra are characteristic of polypropylene, and are thus evidence for its presence in post-consumer HDPE. These quantitative MAS spectra made it possible to estimate the PP content of HDPE (Table 2). In addition, short chain branching was evident in the PE100 spectra, which is in accordance with the characteristics of this high performance grade plastic $[12,18]$. (The Discussion further elaborates on these findings.)

Figure 4.

The clearly visible branched fractions in the NMR ${ }^{13} \mathrm{C}$ CPMAS spectra of PE100 and variations in the molar mass distribution have a significant impact on material performance. Distributions of molecular weights can be described in multiple ways: One commonly used method is based on the molecular weight moments $M_{n}$ and $M_{w}$, which are the number average and the weight average, respectively; another method consists of comparing the rheological properties of the resins, such as the melt flow index (MFI).

\section{Figure 5.}

Figure 5 presents the size-exclusion chromatography (SEC) curves of the HDPE samples; virgin HDPE is clearly different to non-virgin HDPE, as can be seen by the bimodal character of the molar weight distribution of PE100, as expected due to the tandem reactor synthesis., and compared to the quasi-unimodal distribution of the other HDPE (see Table 3). This result is consistent with the presence of short chain branching suggested by the NMR spectra. In more detail, the molar weight distribution of HDPE-R is broader than HDPE-M and HDPE-P.

Table 3. Molecular and thermal characteristics of HDPE resins

\begin{tabular}{cccccccc}
\hline $\begin{array}{c}\text { Sample } \\
\text { code }\end{array}$ & $\begin{array}{c}\text { Mn } \\
\mathbf{k g} / \mathbf{m o l}\end{array}$ & $\begin{array}{c}\text { Mw } \\
\mathbf{k g} / \mathbf{m o l}\end{array}$ & $\mathbf{D}$ & $\begin{array}{c}\text { OIT } \\
\mathbf{m i n}\end{array}$ & $\begin{array}{c}\mathbf{X c} \\
\mathbf{w t} \%\end{array}$ & $\begin{array}{c}\left.\mathbf{M F I} \mathbf{I}^{\mathbf{a}}\right) \\
\mathbf{g} / \mathbf{1 0 m i n}\end{array}$ \\
\hline PE100, a & 22.2 & 165 & 7.5 & 125 & $61.0 \%( \pm 0,4)$ & 0.30 \\
HDPE-M, b & 25.2 & 131 & 5.2 & 33 & $58.7 \%( \pm 1,5)$ & 1.10 \\
\hline
\end{tabular}




\begin{tabular}{ccccccc}
\hline HDPE-R, c & 24.8 & 150 & 6.1 & 107 & $60.4 \%( \pm 1,8)$ & 0.56 \\
HDPE-P, d & 24.3 & 125 & 5.2 & 70 & $60.0 \%( \pm 1,4)$ & 1.60 \\
\hline
\end{tabular}

${ }^{\text {a) }} \mathrm{MFI}=\mathrm{g} / 10 \mathrm{~min}\left(190^{\circ} \mathrm{C}, 5 \mathrm{~kg}\right)$

\section{Physical properties}

The degree of crystallinity of a polymer affects its physical and mechanical properties such as yield stress, Young's modulus and density [9]. For the present study, the degree of crystallinity was around $60 \mathrm{wt} \%$ with a slightly lower value for HDPE-M; these values were established through thermal analysis (DSC). The melt flow index (MFI) is another useful tool for assessing changes in the molecular weight of a polymer. Table 3 shows the expected inverse correlation between the MFI values and the molecular weights (Mw) of the various HDPE samples.

\section{Discussion}

To understand the mechanical properties of HDPE plastics, it is first necessary to consider these thermoplastic polymers as an alloy of "hard-phase" crystal lamella dispersed in an amorphous "soft-phase" region. These two regions are linked by tie molecules that are compatible with both phases. Note that, in the amorphous region, the macromolecules have high local mobility, which is, however, limited by numerous entanglements such as twists, knots and loops. Concerning Young's modulus and yield strength values (Table 1), they are primarily controlled by the composition of the crystalline "hard-phase". The four types of HDPE investigated in this study had a nearly identical degree of crystallinity (about 60\%). However, modulus and yield strength values differed widely, ranging from 670 to $930 \mathrm{MPa}$ and from 24.8 to $30.5 \mathrm{MPa}$, respectively. These unexpected changes in the short-term mechanical performance of the resins were probably caused by the presence of filler residues and black carbon in the material. For instance, although HDPE-M presented a lower degree of crystallinity and a higher Young's modulus, it contained more than twice the amount of black carbon than the other HDPE samples.

To understand the creep and fatigue properties, two additional important parameters must be considered: the average molecular weight and the comonomer content of the polymer. In the PE100 resin, the high performances of the long-term mechanical properties depend on the amount of comonomer, the density of short chain branching and the average molar weight. For instance, in the present work, the signals of the ${ }^{13} \mathrm{C}$ NMR spectra observed on PE100 at concentrations of 39.5 ppm (branched carbon), 24 ppm and 15 ppm (methyl group) indicated the presence of short branches in the statistic copolymer. Signals in the 
observed bands of the ${ }^{13} \mathrm{C}$ NMR spectra were assigned to the usual chemical structures according to [18]. The presence of these long chains, which carry out the links between hard and amorphous regions in the polymer, contributes to increase the amount of tie molecules. In addition, the short chain branching decreases the local mobility of the chain, decreases the crystallinity and increases the entanglements. However, the presence of statistical copolymer has also a negative effect by increasing the viscosity and decreasing the processability of the resin. In PE100 resins, linear homopolymers were added to counterbalance these unwanted effects. As a result, the mechanical measurements showed that synthesizing bimodal polyethylene produced materials with greater stiffness, greater toughness and improved longterm resistance without loss of processability compared with unimodal resins.

Concerning the molecular weight distributions of recycled polyethylene produced from post-industrial and post-consumer waste, they were unimodal or almost unimodal with a lower average molecular weight (Mw) (Table 3). In fact, the recycling process is generally assumed to generate chain scission, branching and crosslinking, resulting from various reactions involving free radicals. HDPE presumably has a higher tendency for crosslinking than for molecular weight reduction. However, Rideal \& Padget [20] concluded that both chain scission and crosslinking are concurrently influenced by shear stress and temperature. Consequently, creep resistance and fatigue values for recycled HDPE were dramatically lower than for PE100 (Figs. 1 and 2-A).

An equally important consideration is the potential presence of fillers and contaminants. Previous studies have suggested that filler materials are added to enhance the mechanical properties of HDPE [21]. In fact, the addition of inorganic particles such as titanium and calcium carbonate can increase material rigidity and toughness and reduce the creep compliance of various polymeric matrices. The formation of cavities surrounding the rigid inorganic particles in the polymer matrix offers a possible explanation for this filler-induced toughening effect. This effect possibly promotes shear yielding, thereby increasing the amount of absorbed energy. In addition, nanoparticles are presumed to restrict the motion of polymer chains, influencing stress transfer at the nanoscale, which increases the creep stability of the material $[22,23]$. Unfortunately, these small particles sometimes accelerate material rupture, especially if the nature and distribution of these particles cannot be sufficiently controlled [14]. For instance, SEM images have revealed the presence of small filler particles at the bottom of these microvoids. Such observations suggest that these particles play an important role as stress concentrators and as facilitators of microvoid nucleation, which promotes crack growth through crazing. Indeed, the development of 
microvoids in HDPE materials under creep load is usually considered the first stage in the breaking process, preceding propagation and total fracture. Ultimate rupture occurs following the propagation of the deformation zone, which initially forms at the tip of a crack. This deformation zone is composed of microscopic cavities (microvoids) that traverse a cross-tied network of fibrillar structures (crazing). In addition, this process (stretching of the fibrils) is presumably controlled by the disentanglement of the tie molecules. The ability of chains to increasingly slip past one another is highly dependent on various molecular and morphological parameters, such as the molecular mass, the molecular mass distribution, the comonomer content and the degree of crystallinity, as already discussed. Thus, the presence of contaminants, old fillers and microparticles, and the absence or low presence of long tie molecules play in the same direction, and decrease synergically the creep resistance and the fatigue properties of the recycled HDPE.

\section{Conclusions}

In this study, we sought to determine whether structural modification and/or contaminants found in recycled and reprocessed polymers affect the long-term loss of mechanical properties. Although the mechanical requirements for sewer pipes are less stringent than those imposed on potable water pressure pipes, long-term performance is an equally important quality in sewer pipe standards and should be investigated thoroughly.

This comparative study between virgin HDPE and three different recycled HDPE has highlighted in particular, thanks to the joint study by XRD, EDX and XPS spectroscopies, the importance of contaminants, polypropylene and fillers in recycled materials. In the same way, the HT-SEC and melt flow index evaluated the changes to the molar mass distribution which we associate with the degradation processes in recycling and reprocessing materials. It should be also stressed that the post-consumer HDPE are originated from sorting of short-life product, with low average molecular weights and, as a consequence, only with a little quantity of tie molecules.

The results revealed the inherent complexity of the studied materials. Based on shortterm mechanical tests as well as FTIR, solid-state NMR, OIT, MFI and XRF data, we successfully demonstrated that today's efficient sorting processes result in good-quality recycled materials. However, the presence of contaminants and filler residue-even of small amounts—clearly had a considerable effect on the long-term properties of these polymers. Furthermore, the results for recycled HDPE highlight the absence of long macromolecules 
and tie macromolecules, both of which play a well-known and essential role in limiting creep and fatigue, and ensuring the preservation of long-term performance characteristics.

Finally, it is possible to conclude that, in order to improve the performance of recycled HDPE from post-consumer waste, two main issues have to be addressed: i) the decrease of material contaminants or the improvement of their compatibility with the HDPE resin, and ii) the increase of tie macromolecules content, e.g. by a more specific and selective sorting process or by externally introducing statistical copolymers with long chains.

\section{Acknowledgments}

The research work was financially supported by the Région Pays de la Loire (under Award \#2012-9615). The authors are grateful to D. Deneele (IFFSTAR) for his assistance in $\mu$-XRF experiments and N.Stephant at the IMN electronic microscopy center for his technical support.

\section{References}

[1] Plastics - the Facts 2013: An analysis of European latest plastics production, demand and waste data. Brussels: PlasticsEurope - Association of Plastics Manufacturers, 2013. Accessed December 2014. http://www.plasticseurope.org/Document/plastics-the-facts2013.

[2] A. Shamiri, M. H. Chakrabarti, S. Jahan, M.A. Hussain, W. Kaminsky, P.V. Aravind, W.A. Yehye. The Influence of Ziegler-Natta and Metallocene Catalysts on Polyolefin Structure, Properties, and Processing Ability. Materials 7 (2014) 5069-5108.

[3] S. Boros. Long-Term Hydrostatic Strength and Design of Thermoplastic Piping Compounds. Journal of ASTM International 8 (2011) 57-72.

[4] Y. Kleiner, B. Rajani. Comprehensive review of structural deterioration of water mains: statistical models. Urban Water 3 (2001) 131-150.

[5] A.E. Bennett, C.M. Rienstra, M. Auger, K. V. Lakshmi, R.G. Griffin. Heteronuclear decoupling in rotating solids. J. Chem. Phys 103 (1995) 6951.

[6] L.L. Bohm, H.F. Enderle, M. Fleifßner. High-density polyethylene pipe resins. Advanced Materials 4 (1992) 234-238. 
[7] L. Hubert, L. David, R. Seguela, G. Vigier, C. Degoulet, Y. Germain. Physical and mechanical properties of polyethylene for pipes in relation to molecular architecture. I. Microstructure and crystallisation kinetics, Polymer 42 (2001) 8425-8434.

[8] R. K. Krishnaswamy. Analysis of ductile and brittle failures from creep rupture testing of high-density polyethylene (HDPE) pipes. Polymer 46 (2005) 11664-11672.

[9] L. H. Sperling. Introduction to physical polymer science. Chapter 11 (4th ed.). Published by John Wiley \& Sons, Inc., Hoboken, New Jersey (2005).

[10] J. G. J. Beijer, J. L. Spoormaker, Modelling of creep behaviour in injection-moulded HDPE. Polymer 41 (2000) 5443-5449.

[11] J. M. L. Reis, L.J. Pacheco, H.S. da Costa Mattos. Temperature and variable strain rate sensitivity in recycled HDPE. Polymer Testing 39 (2014) 30-35.

[12] K. H. Nitta, H. Maeda. Creep behavior of high density polyethylene under a constant true stress. Polymer Testing 29 (2010) 60-65.

[13] M. Parsons, E.V. Stepanov, A. Hiltner, E. Baer. Effect of strain rate on stepwise fatigue and creep slow crack growth in high density polyethylene. Journal of materials science 35 (2000) 1857-1866.

[14] Z. Khan. Fracture Surface Analysis in HDPE Pipe Material Fatigued at Different Temperatures and Loading Frequencies. Journal of materials engineering and performance 21 (2012) 1468-1473.

[15] H. B. H. Hamouda, M. Simoes-Betbeder, F. Grillon, P. Blouet, N. Billon, R. Piques. Creep damage mechanisms in polyethylene gas pipes. Polymer 42 (2001) 5425-5437.

[16] S. Bertin, J.J. Robin. Study and characterization of virgin and recycled LDPE/PP blends. European Polymer Journal 38 (2002) 2255-2264.

[17] P. Rachtanapun, S. E. M. Selke, L. M. Matuana. Relationship between cell morphology and impact strength of microcellular foamed high-density polyethylene/polypropylene blends. Polymer Engineering \& Science 44 (2004) 1551-1560.

[18] G. B. Galland, R. F. de Souza, R. S. Mauler, F. F. Nunes. 13C NMR Determination of the composition of linear low-density polyethylene obtained with [ $\eta 3-$-methallyl-nickeldiimine] PF6 complex. Macromolecules 32 (1999) 1620-1625.

[19] Y. Fan, Y. Xue, W. Nie, X. Ji, S. Bo. Characterization of the microstructure of bimodal HDPE resin. Polymer journal 41 (2009) 622-628.

[20] G. R. Rideal, J. C. Padget. The thermal-mechanical degradation of high density polyethylene. In Journal of Polymer Science: Polymer Symposia 57 (1976) 1-15. 
[21] F. Mijangos-Santiago and J.M. Dealy. Effect of Filler Content and Additives on the Extrudate Swell of Polyethylene Pipe Resin. Polymer Engineering \& Science 31 (1991) 1176-1181.

[22] F. Bondioli, A. Dorigato, P. Fabbri, M. Messori, A. Pegoretti. Improving the creep stability of high-density polyethylene with acicular titania nanoparticles. Journal of applied polymer science 112 (2009) 1045-1055.

[23] F. Bondioli, A. Dorigato P. Fabbri, M. Messori, A. Pegoretti. High-density polyethylene reinforced with submicron titania particles. Polymer Engineering \& Science 48 (2008) 448-457. 


\section{Figure captions}

Figure 1. Creep compliance of different HDPE samples measured on tensile test specimens produced by injection molding: (a) PE100, (b) HDPE-M, c) HDPE-R and d) HDPE-P.

Figure 2. A) Crosshead displacement plotted against number of fatigue test cycles. Tests are performed in load control mode using sinusoidal load cycling with a range of 2 to $18.5 \mathrm{MPa}$ at a frequency of $2 \mathrm{~Hz}$ and a temperature of $26^{\circ} \mathrm{C}$. B) Magnitude of the cyclic stress $(S)$ against the number of cycles to failure $\left(N_{f}\right)$ for the 4 types of studied HDPE at $26{ }^{\circ} \mathrm{C}$. Data are collected repeatedly ( 2 to 3 experiments per experimental condition): a) PE100, b) HDPE-M, c) HDPE-R and d) HDPE-P.

Figure 3. A) SEM image (BSE, mag $=5000 \times$ ) of a typical area of the regenerated HDPE, and the X-ray elemental mappings of $\mathrm{Ti}_{\alpha}$ and $\mathrm{Ca} \mathrm{K}_{\alpha}$ measured on the same area. B) $\mu$-XRF spectra for a) PE100, b) HDPE-M, c) HDPE-R and d) HDPE-P. C) XPS spectra used for quantitative analysis of c) HDPE-R and d) HDPE-P

Figure 4. Solid-state NMR ${ }^{13} \mathrm{C}$ CPMAS spectra of a) virgin bimodal HDPE, b) reprocessed HDPE, c) recycled HDPE. $\mathrm{CH}, \beta-\mathrm{CH}_{2}$ assigned in accordance with [19].

Figure 5. A) Normalized molecular weight distribution measurements obtained through tensile testing of the injection-molded polymer specimens: a) virgin bimodal HDPE, b) mix of virgin and reprocessed HDPE, c) reprocessed HDPE, and d) recycled HDPE. B) Weight average molecular weights $\left(M_{w}\right)$ of virgin and recycled HDPE. 


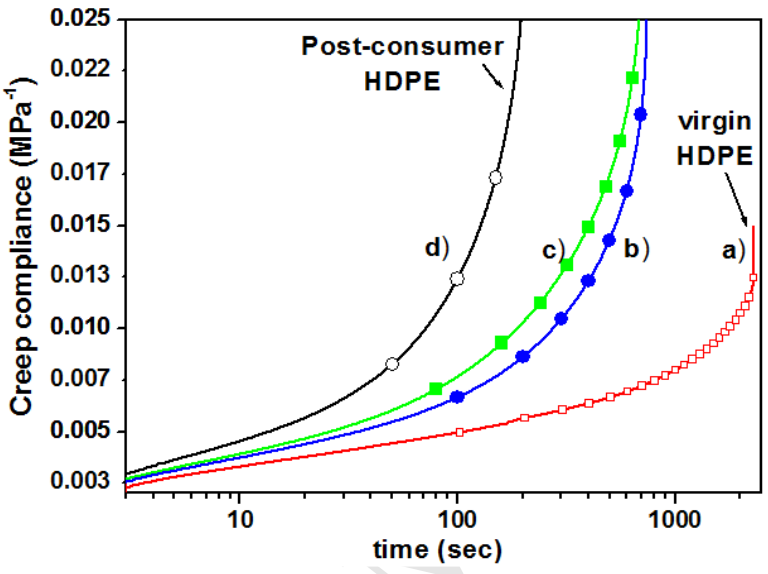

Figure 1 : Alzerreca et al. 

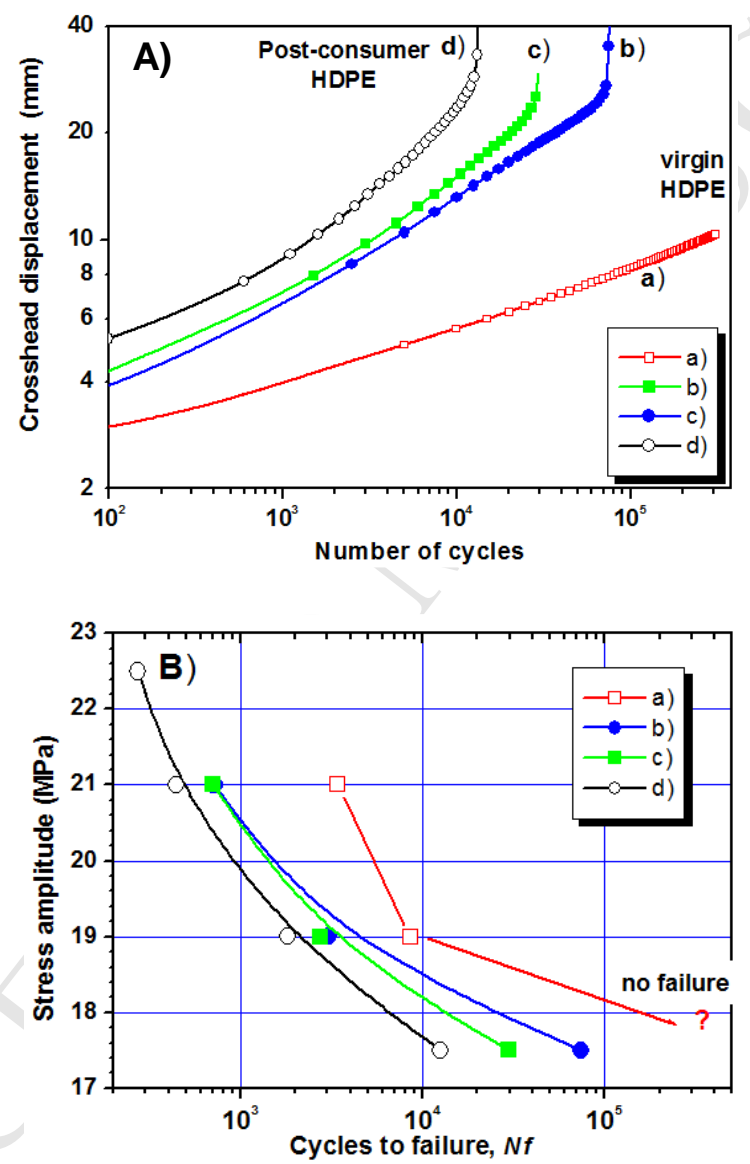

Figure 2 : Alzerreca et al. 

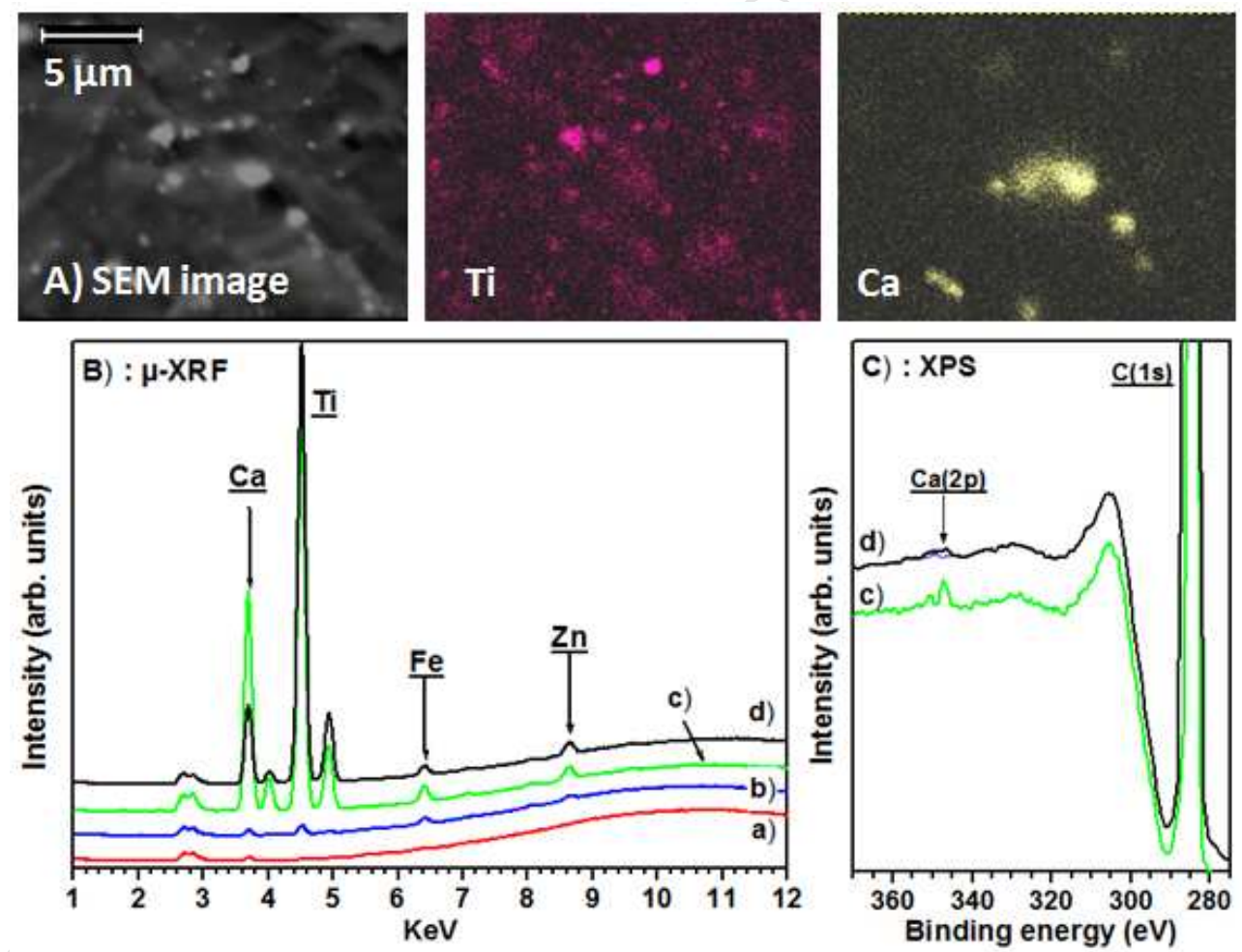

Figure 3 : Alzerreca et al. 


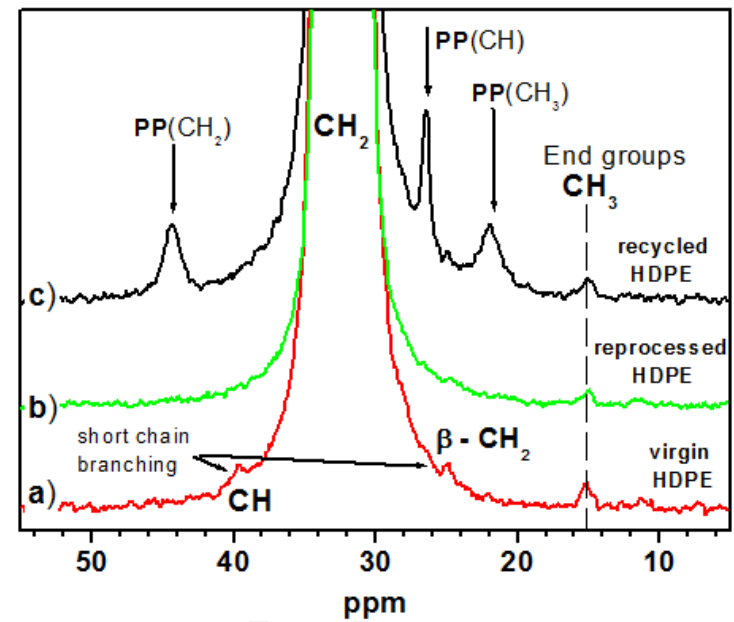

Figure 4 : Alzerreca et al. 

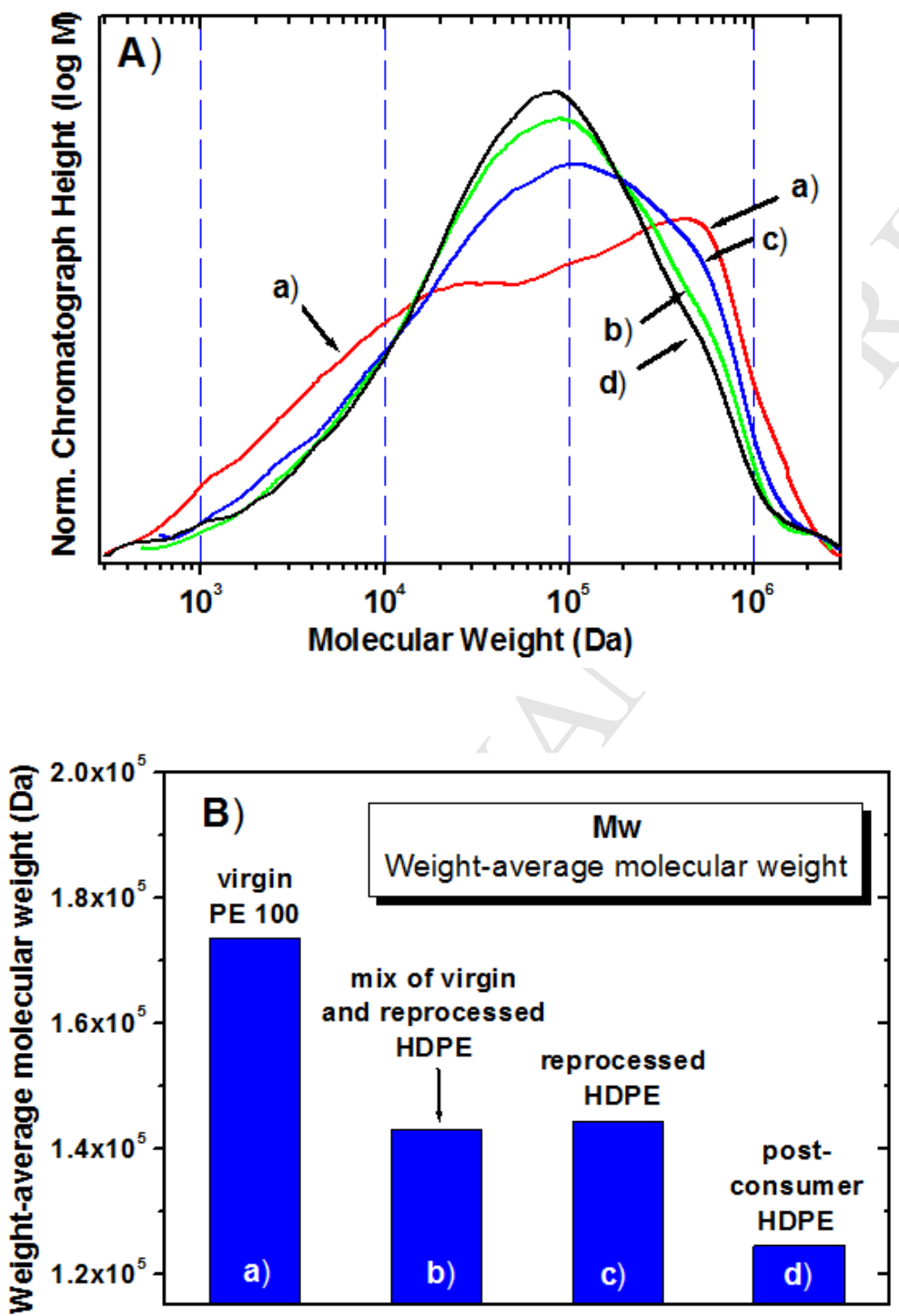

Figure 5 : Alzerreca et al. 


\section{Table Captions}

Table 1. Mechanical characteristics and sample codes of the studied HDPE materials

Table 2. Quantitative analysis of contaminants and residual fillers for various HDPE samples

Table 3. Molecular and thermal characteristics of HDPE resins 


\begin{tabular}{cccccc}
\hline Sample code & $\begin{array}{c}\text { Young's Modulus } \\
(\mathbf{M P a})\end{array}$ & $\begin{array}{c}\text { Yield strength } \\
(\mathbf{M P a})\end{array}$ & $\begin{array}{c}\text { strain at } \\
\text { break } \\
(\%)\end{array}$ & $\begin{array}{c}\text { Strain at } \\
\text { ultimate stress }\end{array}$ \\
\hline PE100, a & $750( \pm 23)$ & $30.5( \pm 0.7)$ & $13 \%( \pm 1)$ & $9.1 \%( \pm 0.2)$ \\
HDPE-M, b & $935( \pm 40)$ & $26.7( \pm 0.2)$ & $22 \%( \pm 1)$ & $9.1 \%( \pm 0.2)$ \\
HDPE-R, c & $870( \pm 34)$ & $26.7( \pm 0.3)$ & $23 \%( \pm 3)$ & $9.6 \%( \pm 0.3)$ \\
HDPE-P, d & $670( \pm 49)$ & $24.8( \pm 0.2)$ & $76 \%( \pm 16)$ & $10.5 \%( \pm 0.1)$ \\
\hline
\end{tabular}

Table 1: Alzerreca et al. 


\begin{tabular}{cccccccc}
\hline \multirow{2}{*}{ Sample code } & $\mathrm{PP}^{\mathrm{a})}$ & $\mathrm{BC})$ & \multicolumn{4}{c}{ Metal $\left(\mathrm{ppm}^{\mathrm{c})}\right)$} & \\
& $\mathrm{wt} \%$ & $\mathrm{wt} \%$ & $\mathrm{Ti}$ & $\mathrm{Ca}$ & $\mathrm{Fe}$ & $\mathrm{Zn}$ & Traces $(<2 \mathrm{ppm})$ \\
\hline PE100 & $<0,1$ & 1.9 & - & 36 & 3 & & $\mathrm{Ti}, \mathrm{K}$ \\
HDPE-M & $<0,1$ & 3.3 & 130 & 125 & 47 & 29 & $\mathrm{Si}, \mathrm{Cu}, \mathrm{P}, \mathrm{S}, \mathrm{Cu}$, \\
HDPE-R & $<0,1$ & 1.0 & 4100 & 2500 & 100 & 64 & $\mathrm{Si}, \mathrm{P}, \mathrm{S}, \mathrm{Cu}$ \\
HDPE-P & $2-3$ & 0.9 & 5400 & 1100 & 78 & & $\mathrm{Zn}, \mathrm{Cu}, \mathrm{Si}, \mathrm{S}, \mathrm{Al}$ \\
\hline
\end{tabular}

${ }^{\text {a) }}$ Polypropylene content based on solid-state ${ }^{13} \mathrm{C}-\mathrm{NMR}$ spectra

b) Black carbon content quantified through TGA analysis using a nitrogen atmosphere

${ }^{\text {c) }}$ Parts per million

Table 2 : Alzerreca et al. 


\begin{tabular}{ccccccccc}
\hline $\begin{array}{c}\text { Sample } \\
\mathbf{c o d e}\end{array}$ & $\begin{array}{c}\mathbf{M n} \\
\mathbf{k g} / \mathbf{m o l}\end{array}$ & $\begin{array}{c}\mathbf{M w} \\
\mathbf{k g} / \mathbf{m o l}\end{array}$ & $\mathbf{D}$ & $\begin{array}{c}\text { OIT } \\
\mathbf{m i n}\end{array}$ & $\begin{array}{c}\mathbf{X c} \\
\mathbf{w t} \%\end{array}$ & $\begin{array}{c}\mathbf{M F I}^{\mathbf{a})} \\
\mathbf{g} / \mathbf{1 0 m i n}\end{array}$ \\
\hline PE100, a & 22.2 & 165 & 7.5 & 125 & $61.0 \%( \pm 0,4)$ & 0.30 \\
\hline HDPE-M, b & 25.2 & 131 & 5.2 & 33 & $58.7 \%( \pm 1,5)$ & 1.10 \\
HDPE-R, c & 24.8 & 150 & 6.1 & 107 & $60.4 \%( \pm 1,8)$ & 0.56 \\
\hline HDPE-P, d & 24.3 & 125 & 5.2 & 70 & $60.0 \%( \pm 1,4)$ & 1.60 \\
\hline
\end{tabular}

${ }^{\mathrm{a})} \mathrm{MFI}=\mathrm{g} / 10 \mathrm{~min}\left(190^{\circ} \mathrm{C}, 5 \mathrm{~kg}\right)$

Table 3 : Alzerreca et al. 